\title{
A PRESENÇA E A CONTRIBUIÇÃO DOS JOGOS LÓGICOS DE TABULEIRO NO PROJETO RONDON
}

\author{
Renato Ribas \\ Universidade Federal do Rio Grande do Sul \\ renato.ribas@ufrgs.br.br \\ Filipe Franz Teske \\ Universidade Federal do Rio Grande do Sul \\ filipe_teske@hotmail.com
}

Liliane Giordani Universidade Federal do Rio Grande do Sul liliane.giordani@ufrgs.br

André Carissimi Universidade Federal do Rio Grande do Sul asc@ufrgs.br

\section{Resumo}

Os jogos lógicos de tabuleiro estiveram presentes no Projeto Rondon, na Operação Bororos, no Estado do Mato Grosso, mais especificamente no município de Barra do Bugres, de 13 a 24 de julho de 2015. Esta atividade, promovida através do Programa de Extensão LoBoGames da Universidade Federal do Rio Grande do Sul (UFRGS), foi apresentada nas três modalidades de prática (jogo de mesa, jogo gigante e jogo vivo) em cinco diferentes regiões e público-alvo da cidade e da zona rural do município. Neste trabalho estão descritas tais atividades assim como alguns relatos que demonstram a sua aceitação nos públicos-alvo. Trata-se de uma proposta inédita como oficina de uma Expedição Rondon, com potencial para ser explorada futuramente por outras equipes de rondonistas.

Palavras-chave: Jogo de tabuleiro. Raciocínio lógico. Projeto Rondon. Oficina

\section{THE PRESENCE AND CONTRIBUTION OF LOGIC BOARD GAMES IN THE RONDON PROJECT}

\begin{abstract}
The logic board games were presente in the Rondon Project, in the Bororos Operation, in Mato Grosso State, more especifically in the Barra do Bugres city, in July 13th - 24th, 2015. This activity, promoted through the Extension Program LoBoGames in the Federal University of Rio Grande do Sul (UFRGS), was introduced through the three ways of practice (the game on the table, the giant game and the life game) in five different regions and audience in the city area and rural communities. In this work are described these activities as well as some comments and opinions that demonstrate the acceptance of such a kind of activity by the target audience. It represents a novel idea of activity in a Rondon Expedition, with potential to be explored in future by other teams.
\end{abstract}

Keywords: Board game. Logic thinking. Rondon Project. Activity

\section{LA PRESENCIA Y LA CONTRIBUCIÓN DE JUEGOS LÓGICOS DE TABLERO EN EL PROYECTO RONDON}

\section{Resumen}

El juegos lógicos de tablero fueron presentados al Proyecto Rondón en la Operación Bororos, en el Estado de Mato Grosso, concretamente en el municipio de Barra do Bugres, 13-24 julio de 2015. Esta actividad, promovida por el Programa de Extensión LoBoGames de la Universidad Federal de Rio Grande do Sul (UFRGS), se presentó en tres tipos de práctica (juego de mesa, juego gigante y juegos en vivo) cinco regiones diferentes del municipio incluyendo el campo. En este trabajo se describen esas actividades, así como algunos informes que muestran su aceptación en el público o " 
Esta es una propuesta sin precedentes como un taller en el Proyeto Rondon, con potencial para ser explotado en el futuro por otros equipos rondonistas.

Palavras clave: Juegos de tablero. Razonamiento lógico. Proyecto Rondon. Taller. 


\section{INTRODUÇÃO}

Nos tempos atuais, com o avanço das tecnologias de comunicação e o acesso cada vez mais rápido à informação, o valor do conteúdo como conhecimento tem demandado mais esforços para a promoção de espaços de aprendizagem que potencializem o desenvolvimento do raciocínio lógico e do pensamento crítico. Em termos de conteúdo, praticamente tudo pode ser descoberto e aprendido com o auxílio da Internet. Porém, aprender a pensar, usar eficientemente este saber, ter um raciocínio lógico suficiente para nos auxiliar nas escolhas e decisões requer mais do que leitura e acesso à informação, é necessário um exercício mental diário, uma aeróbica neuronal (a neuroaeróbica). Estar com a mente ativa e criativa tem impacto direto no progresso de projetos pessoais e profissionais, bem como na construção de oportunidades e de novas perspectivas. Em todas as faixas etárias, o exercício e o desenvolvimento de tal capacidade tem impacto direto na qualidade de vida das pessoas.

O Projeto Rondon, do Ministério da Defesa, foi promovido nas décadas de 70 e 80, e, após uns 15 anos de interrupção, voltou a ser reeditado em 2005. O seu formato mudou um pouco, ampliou as áreas de atuação e tem procurado ser menos assistencialista do que era antes. Neste novo modelo, o objetivo principal é oportunizar universitários dos grandes centros a conhecerem um pouco das regiões mais remotas do país, seu povo, sua realidade, "um Brasil além dos livros". Por outro lado, espera-se que os trabalhos desenvolvidos nas operações deixem algo para as comunidades locais, uma pequena semente de mudança e perspectivas para estas populações visitadas.

Apresentamos neste trabalho uma atividade (ou oficina) com jogos lógicos de tabuleiro, registrada como Programa de Extensão na Universidade Federal do Rio Grande do Sul (UFRGS), que procura atender os objetivos e anseios discutidos acima. São vários jogos de tabuleiro, organizados de forma didática e praticados em três modalidades (mesa, gigante e vivo, ou humano), que incentivam o exercício lógico mental através do lúdico e com uma interessante bagagem cultural, histórica e geográfica. A diversidade dos jogos tem atraído a atenção do público alvo, assim como o fato de vários deles serem muito simples de aprender e de certa forma rápidos de praticar. Além disso, as modalidades dos jogos gigante e vivo, jogado no chão, trazem um componente importante de socialização devido à intensa interação pessoal requerida nesses dois casos. O artigo descreve a aplicação deste Programa de Extensão em uma operação do Projeto Rondon, com potencial para ser explorada em outras edições. 


\section{PROJETO LOBOGAMES - JOGOS LÓGICOS DE TABULEIRO}

O Programa de Extensão Jogos Lógicos de Tabuleiro (LoBoGames) da UFRGS iniciou, informalmente, em 2012 com atividades isoladas, foi registrado em 2013 como um Projeto de Extensão e em 2014/2015 como Programa (GIORDANI; RIBAS, 2013). O crescente interesse do público em geral em relação às atividades promovidas tem surpreendido os seus coordenadores. O seu potencial em diversos eixos de atuação com atividade recreativa, escolar educativa, formação de líderes e gestores, socialização de grupos, entre outros, também parece ser um fator ainda em expansão (KISHIMOTO, 2005; GIORDANI, 2015).

É quase uma centena de jogos lógicos de tabuleiro (ou jogos abstratos de estratégia), do mundo todo, organizados didaticamente em módulos segundo seu princípio de funcionamento e em ordem crescente de complexidade, conforme observado na Ilustração 1. Estão inclusos desde jogos populares como Dama e Xadrez até jogos menos conhecidos como Pong Hau K’i (da China e Coréia) e o Mu Torere (da Nova Zelândia). É válido mencionar, particularmente, o Jogo da Onça, um jogo de caça, sendo o único jogo de tabuleiro encontrado entre os indígenas brasileiros, e os jogos de origem africana como Shisima, Tsoro Yamatatu e Mancala (ALLUÉ, 2002; RIPOLL; CURTO, 2011).

Além do tradicional jogo sobre a mesa, com tabuleiros de papel e tampas de garrafa PET, onde há uma disputa entre indivíduos, são apresentadas também as modalidades do jogo gigante e do jogo vivo (ou humano). No jogo gigante, com o tabuleiro desenhado no chão e as peças sendo garrafas PET, é possível realizar as disputas em duplas ou trios, criando um espírito de equipe e de negociação entre os pares para a escolha da melhor jogada. Já no jogo vivo, também desenhado no chão, as pessoas são as peças do tabuleiro e quem está do lado de fora não interfere nas decisões das jogadas. As relações interpessoais são intensificadas e vários perfis são rapidamente identificados entre os jogadores, possibilitando interações sociais e otimizando a convivência entre pares (OLIVEIRA, 2004).

Dentre as atividades promovidas pelo Programa LoBoGames estão as oficinas em escolas diretamente com os alunos (desde a educação infantil ao ensino médio), a formação de professores, oficinas com a melhor idade, atividades recreativas em festividades (para todas as idades), atividades com grupos escoteiros e associações comunitárias como AABB Comunidade, entre outras. Nos últimos dois anos foram registradas mais de 1500 pessoas em contato direto com as atividades propostas pelo projeto. A criação de jogos de mesa e gigante com material reciclável bem como o trabalho artístico também é um viés explorado pelo Programa. 


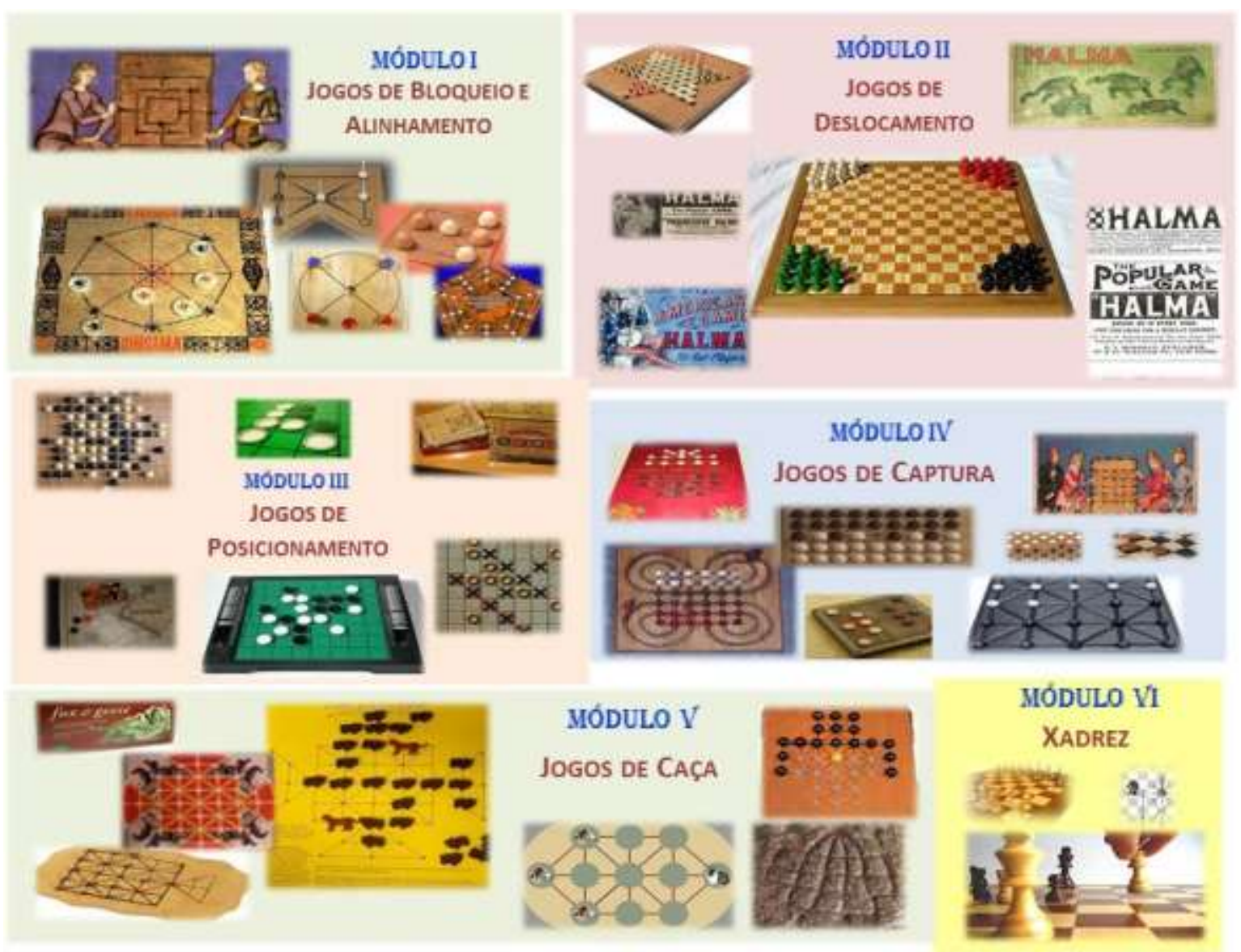

Ilustração 1 - Módulos dos jogos no Projeto LoBoGames.

Fonte: Renato P. Ribas, 2015.

\section{OPERAÇÃO BOROROS - BARRA DO BUGRES, MT}

A Operação Bororos, do Projeto Rondon, ocorreu no Estado do Mato Grosso, de 10 a 26 de julho de 2015, sendo 15 municípios sede e 30 equipes universitárias de rondonistas. As equipes das universidades federais do Rio Grande do Sul (UFRGS) e de São Carlos (UFSCar) atuaram na cidade de Barra do Bugres, com oficinas tanto nas áreas de saúde, educação e cultura quanto de tecnologia e comunicação.

Além das atividades na sede, mais especificamente na Escola Estadual Guiomar, no Bairro Maracanã, na periferia da cidade, os jogos de tabuleiro estiveram presentes na zona rural do município, sendo no distrito de Nova Fernandópolis, no povoado de Currupira, nos assentamentos de Cabaças e Antônio Conselheiro, na região quilombola de Baixius e na aldeia indígena de Umutina.

Os jogos foram apresentados pelos rondonistas nas suas três modalidades de prática para públicos de todas as idades. No último dia de atividades, na Escola Guiomar, a equipe da 
UFRGS promoveu uma mini gincana que incluía alguns jogos de mesa e no chão (gigante e vivo) que haviam sido pintados no pátio da escola.

\section{A CONTRIBUIÇÃO DOS JOGOS NO RONDON}

De forma geral, em todos os grupos atendidos, os jogos de tabuleiro despertaram o mesmo interesse nas pessoas já observado anteriormente nas atividades regulares do Programa LoBoGames, independente da faixa etária.

Na Escola Municipal Guiomar de Campos Miranda, conforme visto na Ilustração 2, no primeiro dia, houve um maior envolvimento dos adultos com o jogo vivo Tapatan (das Filipinas), colocando lado-a-lado na diversão (nas disputas) professores, funcionários da escola, alunos e funcionários da prefeitura. O diretor da escola, Prof. Juvenor de Almeida Arriola, nos autorizou pintar parte do piso externo e mesas de pedra presentes no pátio tabuleiros para que ficassem como atividade de intervalo para os alunos, conforme visto na Ilustração 3.

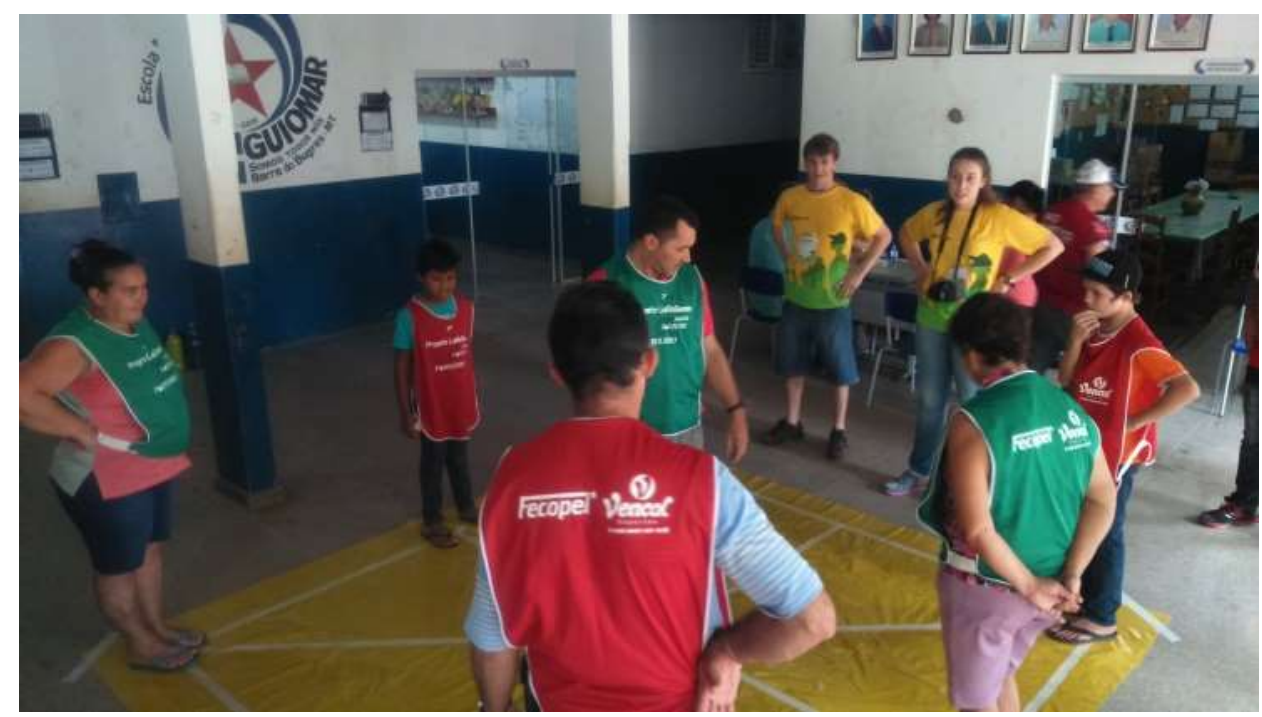

Ilustração 2 - Jogo vivo (Tapatan) na Escola Guiomar.

Fonte: Renato P. Ribas, 2015. 


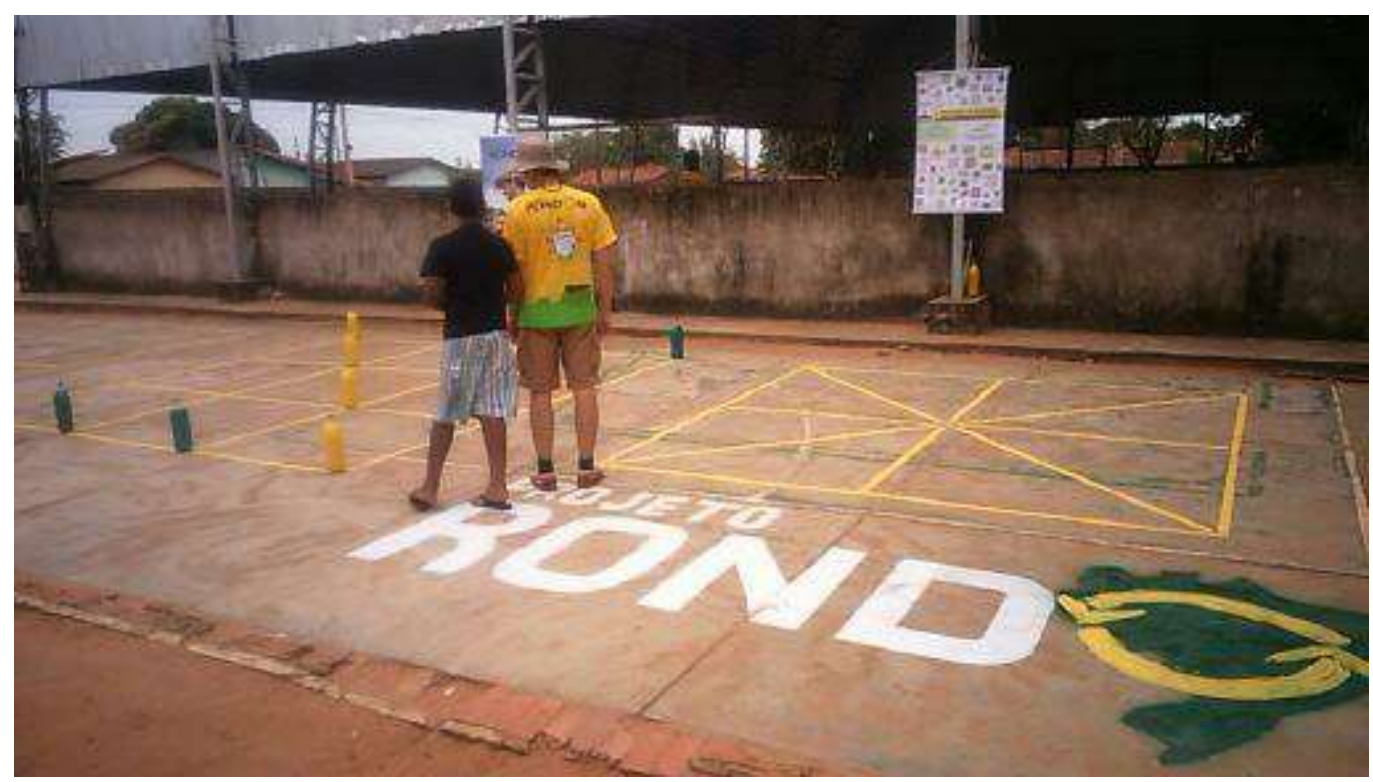

Ilustração 3 - Pintura do pátio da Escola Guiomar. Fonte: Renato P. Ribas, 2015.

No povoado de Currupira, observado na Ilustração 4, nos chamou a atenção a facilidade de aprendizado das crianças e jovens em relação aos jogos que eles nunca tinham visto. Fez-se um registro histórico de um menino de 12 anos, Juan, vindo do assentamento João-e-Maria, que conheceu e aprendeu sozinho a solucionar o desafio do jogo Frog Hop, no qual deve-se trocar 3 peças de cada lado de um tabuleiro em linha sem nunca recuar as peças. Ele demonstrou a solução de olhos fechados! Este experiência em Currupira nos fez pensar em quantos talentos e jovens com potencial intelectual existem nas regiões mais remotas do nosso país, e que não possuem perspectivas ou meios para contribuírem para a sociedade como uma força de trabalho qualificada. 


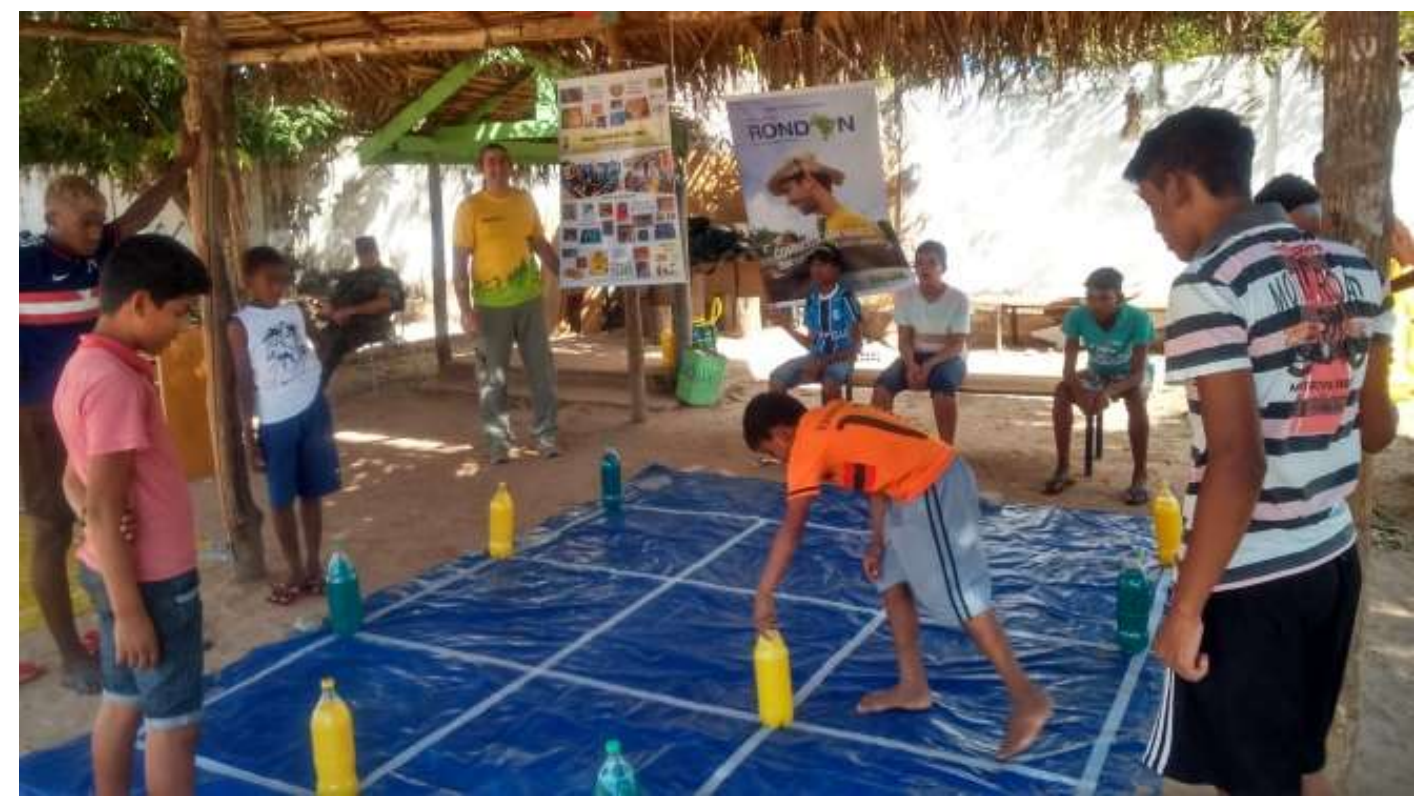

Ilustração 4 - Jogo gigante no povoado Currupira. Fonte: Renato P. Ribas, 2015.

Em Cabaças, os jogos também atraíram grande atenção das diferentes faixas etárias, durante todo o dia de atividades neste povoado, conforme observado na Ilustração 5. O diretor da Escola São Benedito, Prof. Manoel da Guia Ferreira, comentou inclusive que gostaria de pintar os tabuleiros no chão pois os jogos gigante e vivo apresentados em lona prenderam a atenção dos jovens do ensino médio durante a toda tarde, conforme observado na Ilustração 6. Algo difícil da escola conseguir, segundo o diretor, pois esses jovens passam as tarde no mato "queimando lenha para fazer carvão" para conseguir um pouco de dinheiro.

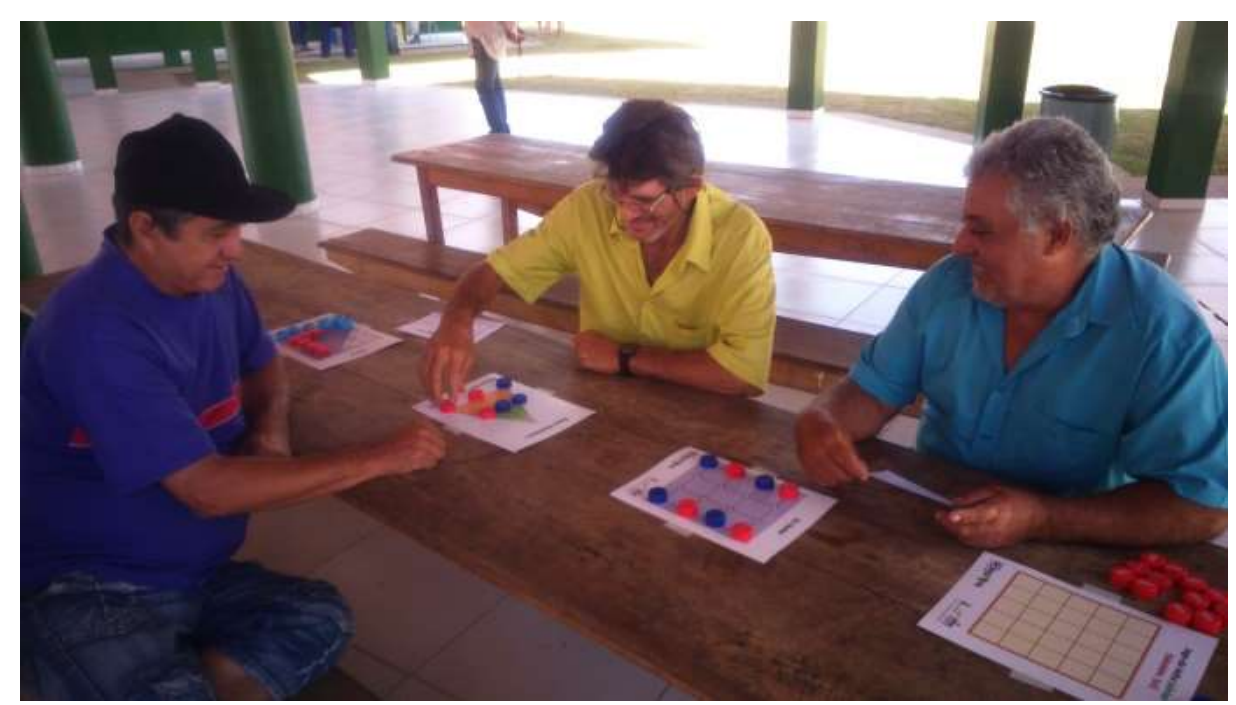

Ilustração 5 - Jogo de mesa no povoado Cabaças. Fonte: Renato P. Ribas, 2015. 


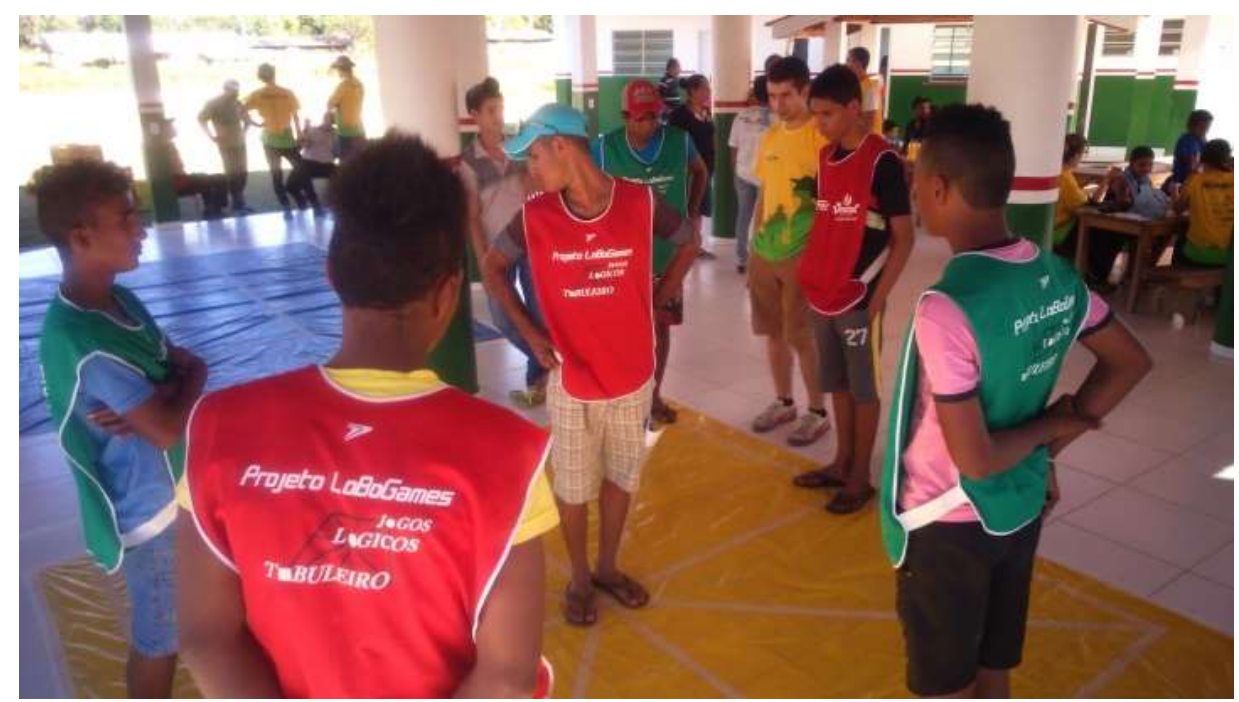

Ilustração 6 - Jogo gigante no povoado de Cabaças. Fonte: Renato P. Ribas, 2015.

$\mathrm{Na}$ aldeia Umutina, conforme observado nas Ilustrações 7 e 8 , e no assentamento Antônio Conselheiro, observado na Ilustração 9, a facilidade em aprender os jogos, bem como o interesse pelas três modalidades de disputa acompanharam o que já vinha sendo observado em outras oportunidades.

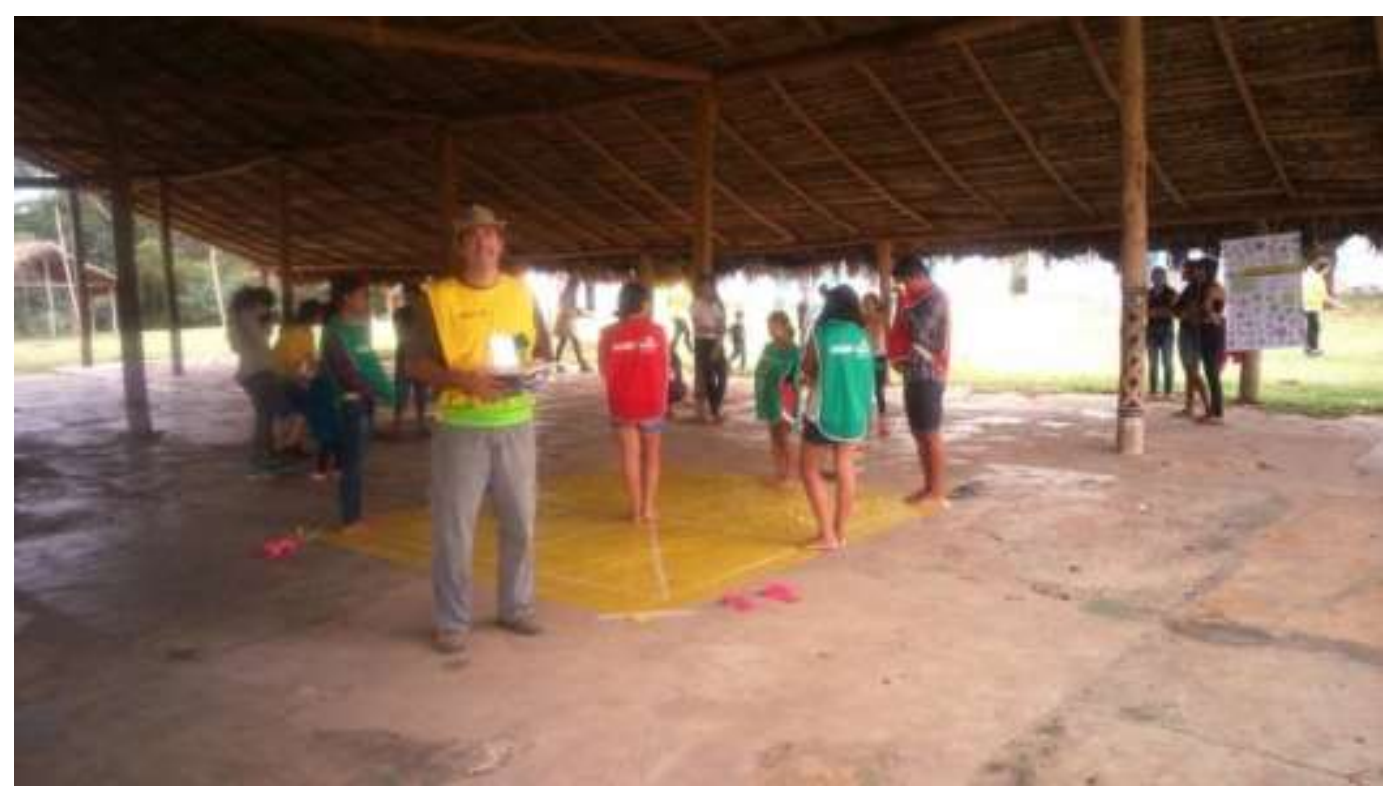

Ilustração 7 - Jogo gigante na aldeia Umutina. Fonte: Renato P. Ribas, 2015. 


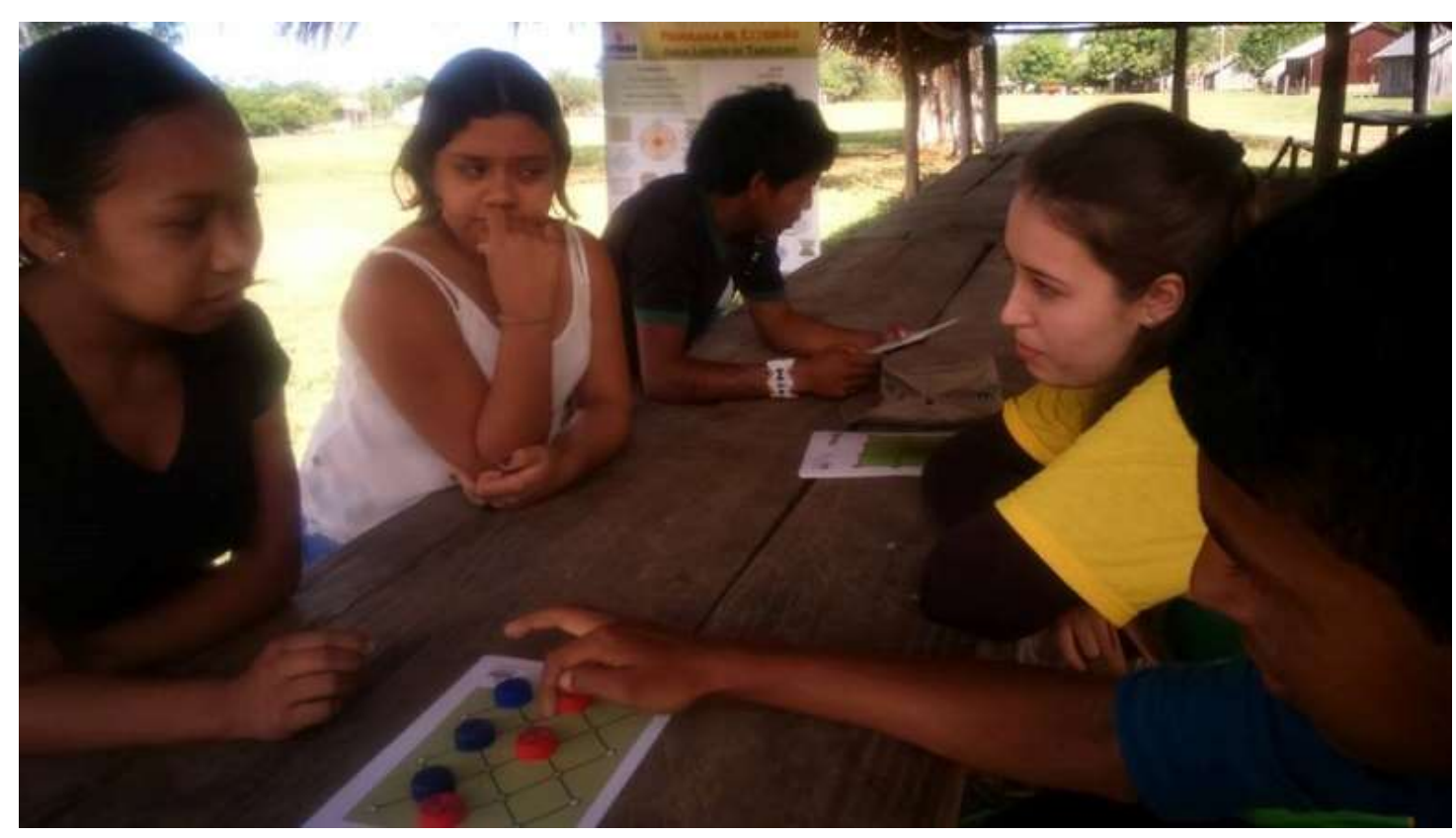

Ilustração 8 - Jogo de mesa na aldeia Umutina. Fonte: Renato P. Ribas, 2015.

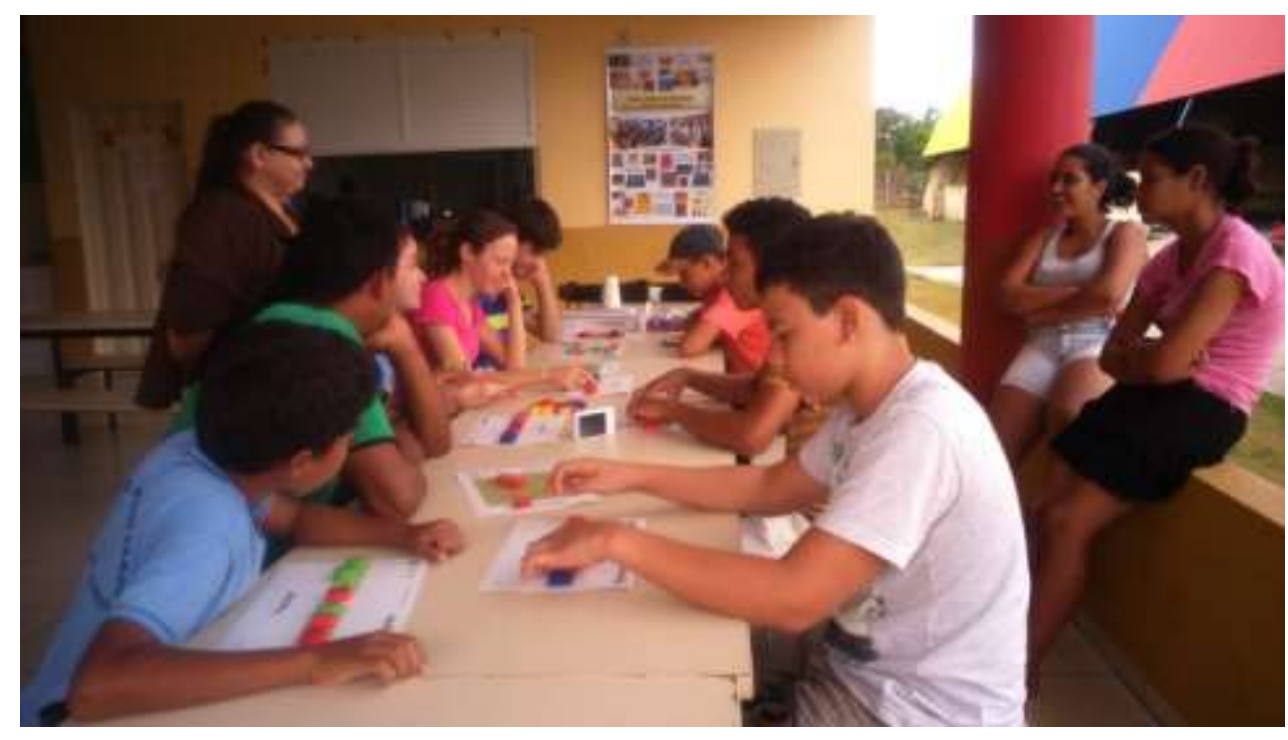

Ilustração 9 - Jogo de mesa no assentamento Antônio Conselheiro. Fonte: Renato P. Ribas, 2015.

No distrito de Nova Fernandópolis, observado nas Ilustrações 10 e 11, o diretor da Escola Municipal Raimunda Arnalda Leão, Prof. Paulo Marcos Ferreira Andrade, solicitou mais informações sobre os jogos para incluir no PNAIC de Matemática, do Ministério de Educação, do qual a escola participa. Dentre todos os espaços que a equipe da UFRGS atuou em Barra do Bugres, os jogos só não foram apresentados no distrito de Assari. 


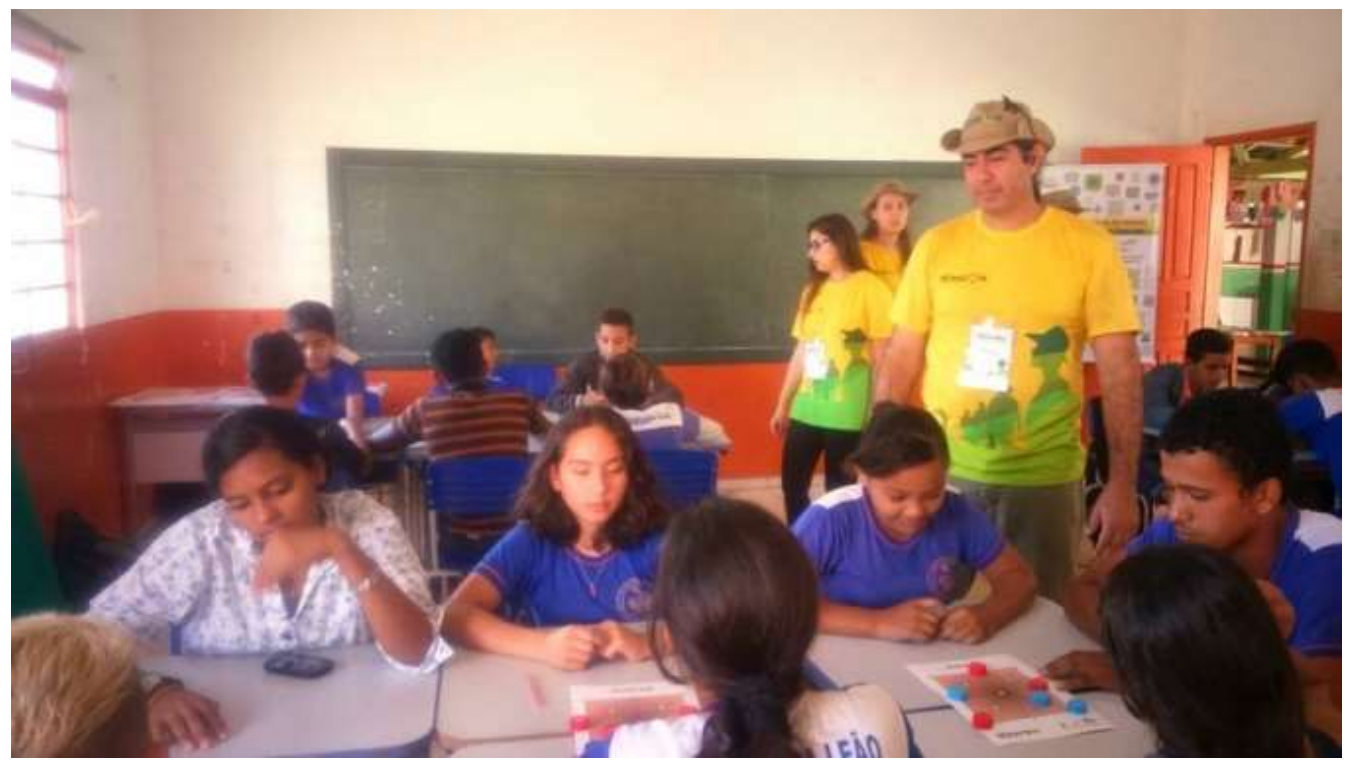

Ilustração 10 - Jogo de mesa no distrito de Nova Fernandópolis. Fonte: Renato P. Ribas, 2015.

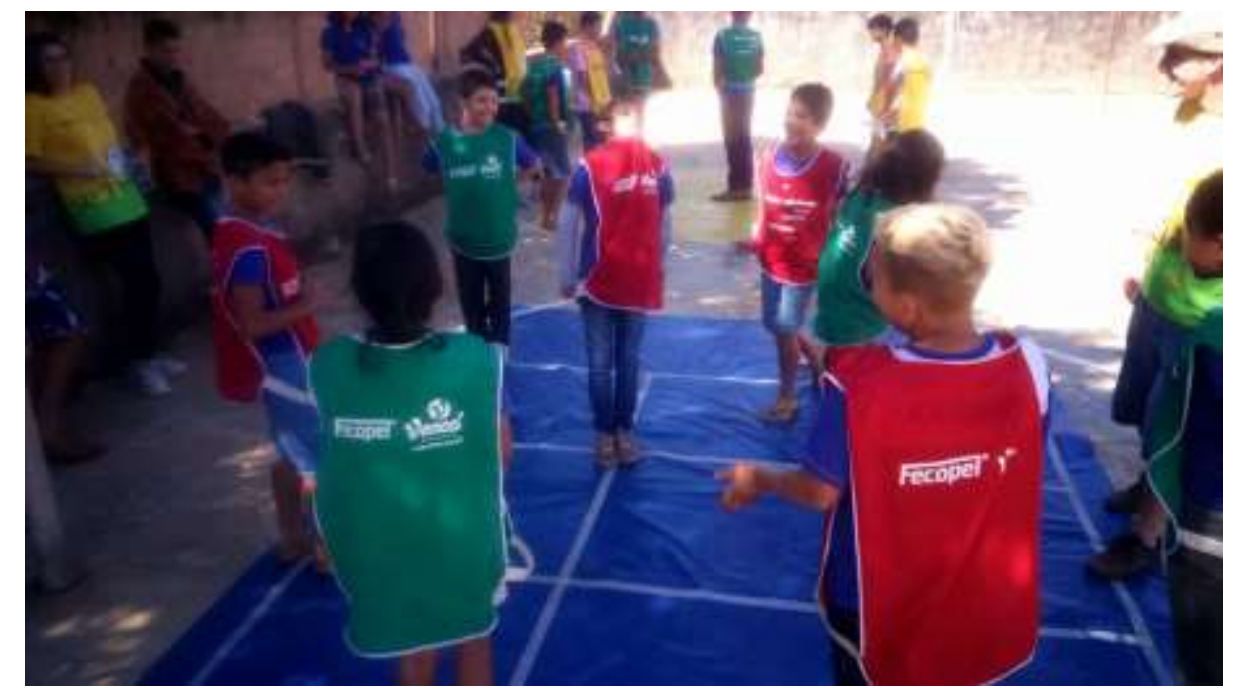

Ilustração 11 - Jogo vivo no distrito de Nova Fernandópolis. Fonte: Renato P. Ribas, 2015.

\section{CONSIDERAÇÕES FINAIS}

A proposta das atividades promovidas pelo Programa de Extensão Jogos Lógicos de Tabuleiro da UFRGS foi apresentada com sucesso na Operação Bororos do Projeto Rondon, em Barra do Bugres, MT. Os relatos dos participantes juntamente com o interesse e envolvimento demonstrado por esses comprovaram o potencial desses jogos como instrumento educativo e recreativo. 
A presença e a contribuição dos jogos lógicos de tabuleiro no Projeto Rondon

Foi observado também o impacto positivo no processo de socialização de grupos, mesmo de faixas etárias heterogêneas. Apesar desta atividade envolver uma disputa, o ganhar e o perder, raramente ocorreu alguma situação de conflito. É como se quem tivesse perdido a disputa (indivíduo ou time) assumisse para si próprio a culpa este insucesso, algo como "falhei na minha análise lógica". Ou seja, o mérito não é necessariamente dado a um adversário mais forte, mas assume-se que a perda da disputa significa que é necessário prestar mais atenção nas jogadas.

Outro fator interessante observado na prática da modalidade do jogo vivo (em equipe), quando as peças são as pessoas e quem esta fora não pode opinar, é a observação dos perfis e personalidades. Esta relação interpessoal resulta em um processo de socialização e integração bem interessante nos grupos. Apenas para constar, neste sentido, alguns desses jogos vivos foram aplicados no processo seletivo da equipe de rondonistas da UFRGS.

Por fim, o custo do material envolvido é bastante baixo pois representam tabuleiros em papel e tampas de garrafa PET para os jogos na mesa, as próprias garrafas PET e fitas adesivas para os jogos gigante e vivo. Esta proposta pode ser facilmente incorporada por outras equipes de rondonistas, sendo que a maior parte das informações necessárias para apropriação desta proposta está disponível em www.inf.ufrgs.br/lobogames.

\section{REFERÊNCIAS}

ALLUÉ, Josep M. Jogos para Todo o Ano - primavera, verão, outono e inverno. São Paulo: Editora Ciranda Cultural, 2002.

GIORDANI, Liliane F.; RIBAS, Renato P. Jogos de Raciocínio Lógico na Escolarização de Surdos: promovendo movimentos no currículo. Anais do VIII Congresso Internacional de Educação e III Congresso Internacional de Avaliação, 2013, Gramado, RS.

GIORDANI, Liliane F. Movimentos no Currículo, Formação de Professores e Outras Aprendizagens. Anais do $6^{\circ}$ Seminário Brasileiro de estudos Culturais e Educação (SBECE), 2015, Canoas, RS.

KISHIMOTO, Tizuko. O Jogo e a Educação Infantil. Florianópolis: Perspectiva, UFSC/CED, NUP, n.22, 2005. 
A presença e a contribuição dos jogos lógicos de tabuleiro no Projeto Rondon

OLIVEIRA, Vera Barros de. Jogos de Regras e a Resolução de Problemas. Petrópolis: Editora Vozes, 2. ed., 2004.

RIPOLL, Oriol; CURTO, Rosa Maria. Jogos de Todo o Mundo. São Paulo: Editora Ciranda Cultural, 2011. 